\title{
Electrochemical and AFM studies on adsorption behavior of a Polynuclear Schiff Base at carbon steel in $\mathrm{HCl}$ medium
}

\author{
Shaju K Shanmughan, Joby Thomas Kakkassery*, Vinod P Raphael and Nimmy Kuriakose
}

Research Division, Department of Chemistry, St.Thomas' College [Autonomous] (University of Calicut) Thrissur, Kerala, India

\begin{tabular}{l}
\hline C H R O N I C L E \\
\hline Article history: \\
Received October 21, 2014 \\
Received in revised form \\
January 29, 2015 \\
Accepted 5 February 2015 \\
Available online \\
5 February 2015 \\
\hline Keywords: \\
Carbon Steel \\
Corrosion Inhibitors \\
Impedance \\
Adsorption \\
AFM
\end{tabular}
\begin{abstract}
A B S T R A C T
The adsorption behavior of a potential polynuclear Schiff base, (s)-2-(anthracen-9(10H)ylideneamino)-3-phenyl propanoic acid (A9Y3PPA) on carbon steel (CS) in 1M hydrochloric acid solution has been investigated using weight loss measurements, electrochemical impedance spectroscopy (EIS) and potentiodynamic polarization studies. The surface morphology of the carbon steel specimens in the presence and absence of the inhibitor was evaluated by AFM analysis. The corrosion inhibition efficiencies of parent amine and parent ketone on carbon steel in $1 \mathrm{M} \mathrm{HCl}$ solution have also been investigated using weight loss studies. The adsorption of A9Y3PPA obeys Langmuir adsorption isotherm. Thermodynamic parameters ( $\mathrm{K}_{\mathrm{ads}}, \Delta \mathrm{G}^{0}$ ads $)$ were calculated using the adsorption isotherm. Activation parameters of the corrosion process $\left(\mathrm{E}_{\mathrm{a}}, \Delta \mathrm{H}^{*}\right.$ and $\Delta \mathrm{S}^{*}$ ) were also calculated from the corrosion rates obtained from temperature studies. Tafel plot analysis revealed that A9Y3PPA acts as a mixed type inhibitor. A probable inhibition mechanism was also proposed.
\end{abstract}

\section{Introduction}

It is well known that the use of hydrochloric acid in metal industries for acid pickling, de-scaling and cleaning process are the major reasons for the increase in the dissolution rate of carbon steel. The use of certain organic compounds containing oxygen, nitrogen and sulphur as inhibitors is the most practical method to prevent corrosion of the carbon Steel (CS) in acidic media ${ }^{1-3}$. Compounds with $\pi$ bonds also generally exhibit good inhibitive properties due to interaction of $\pi$-orbital with the metal surface $^{4}$. Schiff bases are organic molecules possessing azomethine linkage and many of them act as effective potential corrosion inhibitors ${ }^{5-8}$. Increasing efforts have been made to study the corrosion behavior of metals and mechanism of inhibition during the past decade mainly through electrochemical investigations ${ }^{9-11}$. In this paper we report the corrosion inhibition behavior of a novel polynuclear Schiff base (A9Y3PPA) derived from anthracene-9 $(10 \mathrm{H})$ - one and (s)-2-amino-3- phenyl propanoic acid in $1 \mathrm{M} \mathrm{HCl}$ solution on $\mathrm{CS}$ at different temperatures. The study was performed by weight loss

\footnotetext{
* Corresponding author. Tel: +919497773468

E-mail address: drjobythomask@gmail.com (J. T. Kakkassery) 
measurements, electrochemical impedance spectroscopy (EIS) and potentiodynamic polarization analysis.

\section{Results and Discussion}

\subsection{Weight loss measurements}

Weight loss of CS specimens in $1 \mathrm{M} \mathrm{HCl}$ at $30^{\circ} \mathrm{C}$ was determined at $24 \mathrm{~h}$ in the presence of various concentrations of inhibitor (A9Y3PPA). The corrosion rates, inhibition efficiencies and surface coverage $(\theta)$ in the presence of inhibitor for CS specimens for the period of $24 \mathrm{~h}$ are shown in the Table 1. Data clearly established that the corrosion rate markedly decreased with inhibitor concentration and inhibition efficiency increased with increasing the concentration of the inhibitor. At the inhibitor concentration of $1.0 \mathrm{mM}$, the maximum $\eta_{\mathrm{w}} \%$ obtained was 92.36, which shows that A9Y3PPA possesses significant corrosion inhibitor properties for CS in $\mathrm{HCl}$.

Table 1. The corrosion rate, percentage of inhibition efficiency and surface coverage ( $\theta$ ) for CS specimens immersed in $1 \mathrm{M} \mathrm{HCl}$ at $30{ }^{\circ} \mathrm{C}$ for $24 \mathrm{~h}$ in the presence and absence of A9Y3PPA

\begin{tabular}{cccc}
\hline $\mathbf{C}(\mathbf{m M})$ & $\begin{array}{c}\text { Corrosion rate } \\
\left(\mathbf{m m y}^{-1}\right)\end{array}$ & $\begin{array}{c}\text { Inhibition } \\
\text { efficiency }\left(\boldsymbol{\eta}_{\mathbf{w}} \text { \%) }\right.\end{array}$ & $\boldsymbol{\theta}$ \\
\hline $\mathbf{0}$ & 6.50 & - & - \\
$\mathbf{0 . 2}$ & 2.80 & 56.91 & 0.57 \\
$\mathbf{0 . 4}$ & 2.33 & 64.11 & 0.64 \\
$\mathbf{0 . 6}$ & 1.74 & 73.26 & 0.73 \\
$\mathbf{0 . 8}$ & 1.11 & 82.96 & 0.83 \\
$\mathbf{1 . 0}$ & 0.50 & 92.36 & 0.92 \\
\hline
\end{tabular}

\subsection{Comparison of inhibition efficiency of Schiff base with its parent compounds}

To compare the inhibition efficiencies of Schiff base, parent ketone (anthracene-9 (10H)-one) and parent amine [(s)-2-amino-3- phenyl propanoic acid], weight loss measurements of CS specimens were performed in $1 \mathrm{M} \mathrm{HCl}$ at $30^{\circ} \mathrm{C}$.

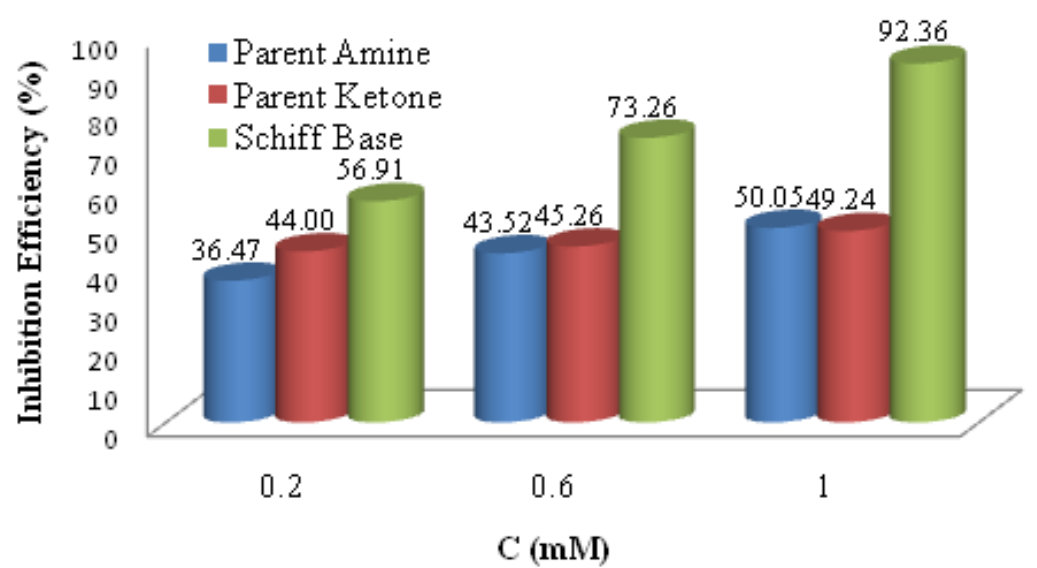

Fig. 1. Comparison of inhibition efficiency of Schiff base, parent ketone and parent amine in $1 \mathrm{M} \mathrm{HCl}$ at $24 \mathrm{~h}$.

The percentage of corrosion inhibition efficiencies obtained for Schiff base, parent ketone and parent amine on CS are represented in the figure 1. The inhibition efficiency of the Schiff base A9Y3PPA was markedly higher than that of parent ketone and parent amine for the studied concentrations. This investigation clearly establish the role of azomethine linkage $(C=N)$ present in the Schiff base which actively participate in the corrosion inhibition mechanism. 


\subsection{Adsorption isotherm and free energy of adsorption}

To elucidate the nature of adsorption and the surface behavior of inhibitor molecules, various adsorption isotherms were assessed in the present study. For the evaluation of thermodynamic parameters it is necessary to determine the best fit isotherm with the aid of correlation coefficient $\left(\mathrm{R}^{2}\right)$. Among the isotherms studied, the best description of the adsorption behavior of A9Y3PPA on CS specimens in $1 \mathrm{M} \mathrm{HCl}$ was Langmuir adsorption isotherm and the model is expressed as ${ }^{12}$

$$
\frac{C}{\theta}=\frac{1}{K_{a d s}}+C
$$

where $\mathrm{C}$ is the concentration of the inhibitor, $\theta$ is the fractional surface coverage and $\mathrm{K}_{\mathrm{ads}}$ is the adsorption equilibrium constant. Figure 2 represents the adsorption plot of A9Y3PPA obtained by the weight loss measurements of CS steel specimens in $1 \mathrm{M} \mathrm{HCl}$ at $30{ }^{\circ} \mathrm{C}$ for $24 \mathrm{~h}$.

The value of adsorption equilibrium constant $K_{\text {ads }}$ is 4397 and is related to the standard free energy of adsorption $\Delta \mathrm{G}^{0}$ ads, by

$$
\Delta \mathrm{G}_{\text {ads }}^{0}=-\mathrm{RT} \ln \left(55.5 \mathrm{~K}_{\mathrm{ads}}\right)
$$

where 55.5 is the molar concentration of water, $\mathrm{R}$ is the universal gas constant and $\mathrm{T}$ is the temperature in Kelvin ${ }^{13} . \Delta \mathrm{G}^{0}$ ads for A9Y3PPA on CS showed negative values indicating the spontaneity of the process.

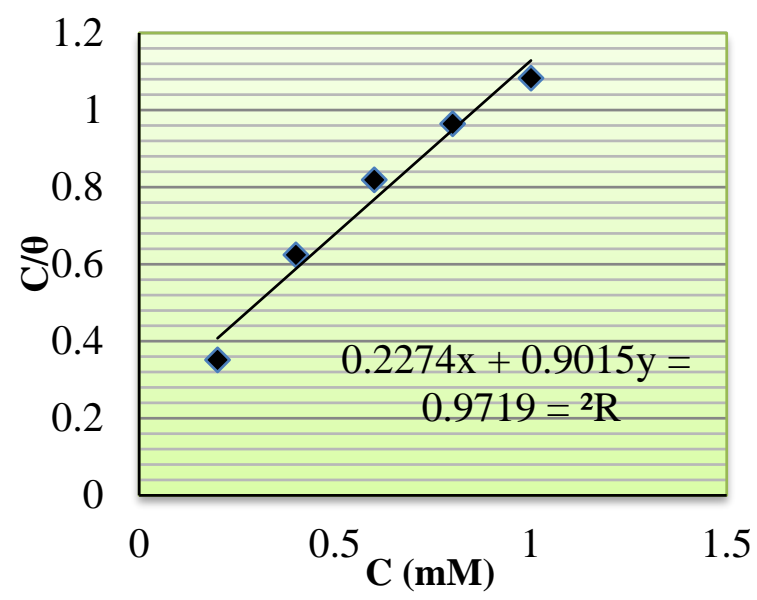

Fig. 2. Langmuir isotherm for adsorption of A9Y3PPA on CS surface in $1 \mathrm{M} \mathrm{HCl}$ at $30{ }^{\circ} \mathrm{C}$ for $24 \mathrm{~h}$

The value of $\Delta \mathrm{G}^{0}$ ads up to $-20 \mathrm{~kJ} \mathrm{~mol}^{-1}$ is an indication of the electrostatic interaction of the charged molecule and the charged surface of the metal (physisorption) while $\Delta \mathrm{G}^{0}$ ads is more negative than -40kJ implies that inhibitor molecules are adsorbed strongly on the metal surface through co-ordinate type bond (chemisorption) $)^{14,15}$. In the present investigation, the inhibitor molecules showed $\Delta \mathrm{G}^{0}$ ads -31.21 $\mathrm{kJ} / \mathrm{mol}$ for CS specimens suggesting that the adsorption of inhibitor involves both electrostatic and chemical interactions.

\subsection{Effect of Temperature}

In order to gain more information about the effectiveness of the A9Y3PPA inhibitor at higher temperature, weight loss measurement in the temperature range of $30-60^{\circ} \mathrm{C}$ was conducted. The activation energy of corrosion with and without the inhibitor could be calculated by Arrhenius equation

$$
K=A \exp \left(-\frac{E_{a}}{R T}\right)
$$

where $\mathrm{K}$ is the rate of corrosion, $\mathrm{E}_{\mathrm{a}}$ the activation energy, $\mathrm{A}$ the frequency factor, $\mathrm{T}$ the temperature in Kelvin scale and $\mathrm{R}$ is the gas constant. Linear plots between logK and 1000/T (Fig. 3) having regression 
coefficients close to unity indicate that the corrosion of CS in $\mathrm{HCl}$ could be explained by the simple kinetic model. Enthalpy and entropy of activation $\left(\Delta \mathrm{H}^{*}, \Delta \mathrm{S}^{*}\right)$ were calculated from the transition state theory $^{16}$

$$
K=\left(\frac{R T}{N h}\right) \exp \left(\frac{\Delta S^{*}}{R}\right) \exp \left(\frac{-\Delta \mathrm{H}^{*}}{\mathrm{RT}}\right),
$$

where $\mathrm{N}$ is the Avogadro number and h is the Planks constant. A plot of log (K/T) Vs 1000/T gave straight lines for the corrosion of $\mathrm{CS}$ in $1 \mathrm{M} \mathrm{HCl}$ in the presence and absence of the inhibitor (Fig. 4). Table 2 shows the activation energy and thermodynamic parameters of corrosion of CS in $1 \mathrm{M} \mathrm{HCl}$ with and without the inhibitor A9Y3PPA. Figure 3 and 4 illustrate that as the concentration of the Schiff base was enhanced, the corrosion rate of the carbon steel specimen diminished appreciably. As the slopes of the straight lines increased with concentration (Fig. 3), one can ascertain that the energy of activation increases with the concentration. In other words, the reluctance of dissolution of metal increased with the inhibitor concentration. Positive signs of enthalpies with a regular rise reflect the endothermic nature of dissolution and the increasing difficulty of corrosion with the inhibitor concentration. It is evident from the Table 2 that the entropy of activation increases with the inhibitor concentration. In the case of blank, the entropy of activation is large and negative. This implies that in the rate determining step, a decrease in disordering takes place on going from reactants to the activated complex and the activated molecules were in higher order state than that at the initial state. But as the concentration of inhibitor increases, the disordering of activated complex rises and the entropy of activation acquires positive values.

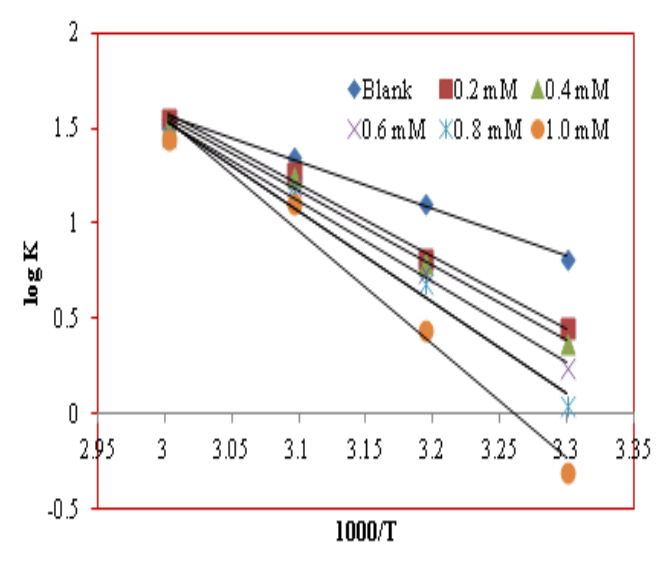

Fig. 3. Arrhenius plots to calculate the activation energy of corrosion of CS in the absence and presence of A9Y3PPA

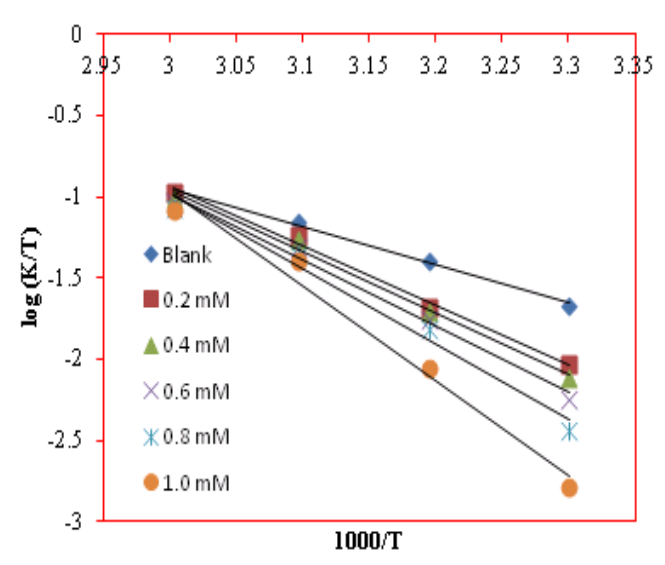

Fig. 4. Plots of $\log (\mathrm{K} / \mathrm{T}) \mathrm{Vs} 1000 / \mathrm{T}$ for the corrosion of CS in the absence and presence of A9Y3PPA

Table 2. Thermodynamic parameters of corrosion of CS in $1 \mathrm{M} \mathrm{HCl}$ with and without the inhibitor A9Y3PPA

\begin{tabular}{|c|c|c|c|c|}
\hline $\mathrm{C}(\mathrm{mM})$ & $\mathrm{E}_{\mathrm{a}}\left(\mathrm{kJ} \mathrm{mol}^{-1}\right)$ & A & $\Delta \mathbf{H}^{*}\left(\mathrm{~kJ} \mathrm{~mol}^{-1}\right)$ & $\Delta \mathrm{S}^{*}\left(\mathrm{~J} \mathrm{~mol}^{-1} \mathrm{~K}^{-1}\right)$ \\
\hline Blank & 47.73 & $1.1 \times 10^{9}$ & 45.09 & -80.44 \\
\hline 0.2 & 72.78 & $9.5 \times 10^{12}$ & 70.13 & -5.15 \\
\hline 0.4 & 75.3 & $2.3 \times 10^{13}$ & 72.66 & 1.94 \\
\hline 0.6 & 81.13 & $1.8 \times 10^{14}$ & 78.48 & 19.17 \\
\hline 0.8 & 91.15 & $6.6 \times 10^{15}$ & 88.49 & 49.04 \\
\hline 1.0 & 114.26 & $2.9 \times 10^{19}$ & 111.6 & 118.73 \\
\hline
\end{tabular}

\section{5 .EIS measurements}

The corrosion behavior of $\mathrm{CS}$ in $1 \mathrm{M} \mathrm{HCl}$ in the presence of various concentrations of inhibitor has been investigated using electrochemical impedance spectroscopy at $30^{\circ} \mathrm{C}$. Figure 5 and 6 represents the Nyquist plots and Bode plots respectively for CS specimens in $1 \mathrm{M} \mathrm{HCl}$ in the presence of various concentrations of inhibitor. It is evident from the plots that the impedance response of metal specimens has marked difference in the presence and absence of the inhibitor A9Y3PPA. 
Impedance behavior can be well explained by pure electric models that could verify and enable to calculate numerical values corresponding to the physical and chemical properties of electrochemical system under examination ${ }^{17}$. The simple equivalent circuit that fit to many electrochemical systems composed of a double layer capacitance, $\mathrm{R}_{\mathrm{s}}$ and $\mathrm{R}_{\mathrm{ct}}{ }^{18,19}$. To reduce the effects due to surface irregularities of metal, constant phase element (CPE) is introduced into the circuit instead of a pure double layer capacitance which gives more accurate fit $^{20}$ as shown in the Fig. 7.

The impedance of CPE can be expressed as $Z_{C P E}=\frac{1}{Y_{0}(j \omega)^{n}}$

where $\mathrm{Y}_{0}$ is the magnitude of CPE, $\mathrm{n}$ is the exponent (phase shift), $\omega$ is the angular frequency and $\mathrm{j}$ is the imaginary unit. CPE may be resistance, capacitance and inductance depending upon the values of $\mathrm{n}^{21}$. In all experiments the observed value of $\mathrm{n}$ ranges between 0.75 and 1.0, suggesting the capacitive response of CPE. The EIS parameters such as $R_{c t}, C_{d l}$ and the calculated values of percentage of inhibition (ךeIS\%) of CS specimens are listed in Table 3.

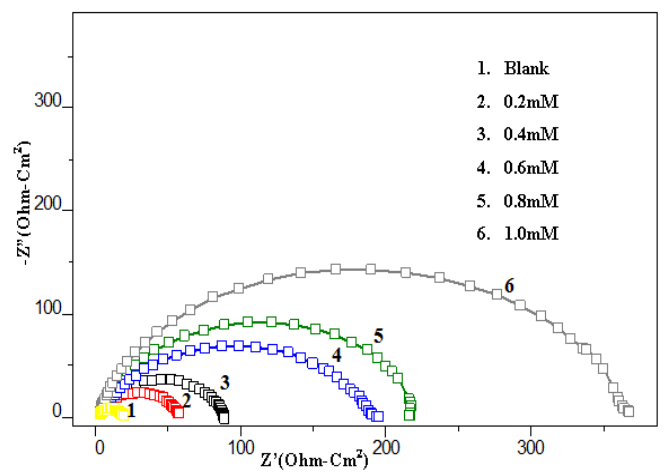

Fig. 5. Nyquist plots for CS specimens in $1 \mathrm{M} \mathrm{HCl}$

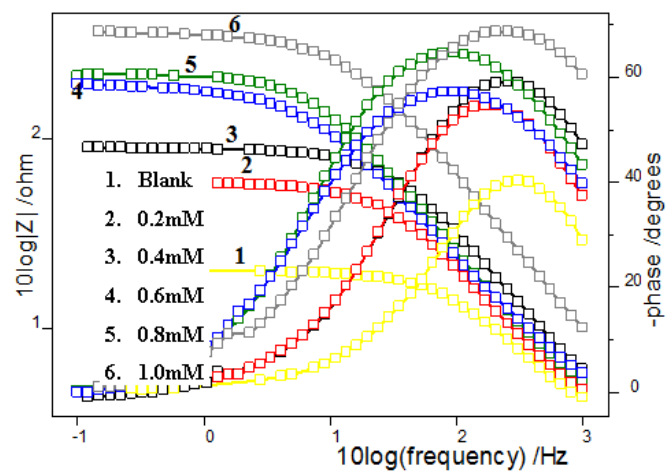

Fig. 6. Bode plots for CS specimens in $1 \mathrm{M} \mathrm{HCl}$

From Table 3 it is clear that $R_{c t}$ values are increased with increasing inhibitor concentration. The capacitance value $\mathrm{C}_{\mathrm{dl}}$ decreases with inhibitor concentration and this decrease in $\mathrm{C}_{\mathrm{dl}}$ may be explained on the basis that the double layer between the charged metal surface and the solution which may act as an electrical capacitor. These results suggest that the A9Y3PPA molecules function by adsorption at the metal/solution interface ${ }^{22}$. A maximum of $95.24 \%$ inhibition efficiency could be achieved at an inhibitor concentration of $1 \mathrm{mM}$ for CS specimen.

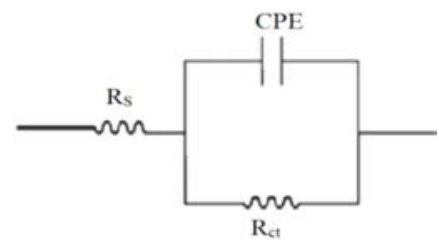

Fig. 7. Equivalent circuit fitting for EIS measurements

Table 3. Electrochemical Impedance parameters of CS specimens in $1 \mathrm{M} \mathrm{HCl}$ at $30^{\circ} \mathrm{C}$ in the absence and presence of inhibitor A9Y3PPA

\begin{tabular}{cccc}
\hline $\mathbf{C}(\mathbf{m M})$ & $\mathbf{R}$ ct $\left(\mathbf{\Omega} \mathbf{c m}^{2}\right)$ & $\mathbf{C}_{\text {dl }}\left(\boldsymbol{\mu} \mathbf{F} \mathbf{~ c m}^{-2}\right)$ & $\eta_{\text {EIS\% }}$ \\
\hline $\mathbf{0}$ & 15.7 & 104 & - \\
$\mathbf{0 . 2}$ & 50.9 & 92.4 & 69.16 \\
$\mathbf{0 . 4}$ & 79.8 & 90.9 & 80.33 \\
$\mathbf{0 . 6}$ & 167 & 83.8 & 90.60 \\
$\mathbf{0 . 8}$ & 203 & 57.1 & 92.27 \\
$\mathbf{1 . 0}$ & 330 & 33.8 & 95.24 \\
\hline
\end{tabular}

\subsection{Potentiodynamic polarization studies}

Fig. 8 and Fig. 9 represents Potentiodynamic and linear polarization curves for CS specimens in $1 \mathrm{M} \mathrm{HCl}$ at $30^{\circ} \mathrm{C}$ in the presence of various concentrations of inhibitor (A9Y3PPA). Polarization 
parameters like corrosion current densities ( $\left.\mathrm{I}_{\mathrm{corr}}\right)$, corrosion potential ( $\left.\mathrm{E}_{\mathrm{corr}}\right)$, cathodic Tafel slope $\left(\mathrm{b}_{\mathrm{c}}\right)$, anodic Tafel slope $\left(b_{a}\right)$, inhibition efficiency $\left(\eta_{\text {pol\% }}\right)$ and linear polarization parameters like polarization resistance $\left(R_{p}\right)$ and inhibition efficiency $(\eta \mathrm{Rp} \%)$ for CS specimens are listed in Table 4. A marked decrease in the corrosion current density ( $\mathrm{I}_{\text {corr }}$ ) was observed in the presence of inhibitor A9Y3PPA. A lowest value of $I_{\text {corr }}$ was noticed for the inhibitor solution of concentration $1 \mathrm{mM}$ which exhibited a maximum inhibition efficiency of $94.86 \%$. The data show that, addition of the Schiff base to acid media affected both the cathodic and anodic parts of the curves; it may be assumed that the inhibitor molecules are adsorbed on anodic and cathodic sites uniformly. Generally if the shift of Ecorr is $>85$ with respect to $E_{\text {corr }}$ of uninhibited solution, the inhibitor can be viewed as either cathodic or anodic type ${ }^{23,24}$. In the present study the maximum shift of $E_{\text {corr }}$ is $30 \mathrm{mV}$, suggesting that A9Y3PPA acts as a mixed type inhibitor for CS specimens in $1 \mathrm{M} \mathrm{HCl}$.

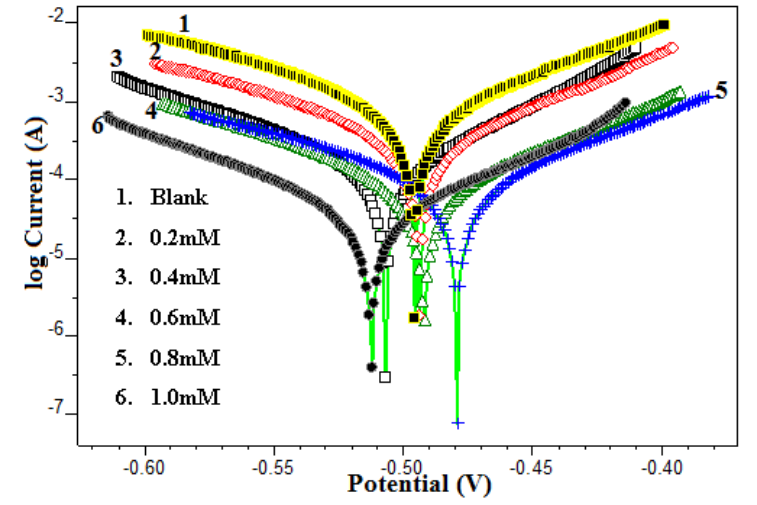

Fig. 8. Tafel plots of CS specimens in $1 \mathrm{M} \mathrm{HCl}$ at 30 ${ }^{0} \mathrm{C}$, with and without inhibitor

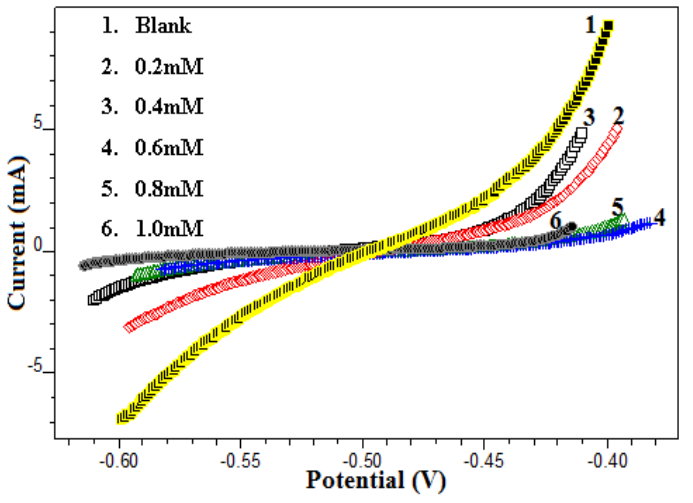

Fig. 9. Linear polarization curves of CS specimens in $1 \mathrm{M} \mathrm{HCl}$ at $30{ }^{\circ} \mathrm{C}$, with and without inhibitor

Table 4. Potentiodynamic and linear polarization parameters of CS specimens in $1 \mathrm{M} \mathrm{HCl}$ at $30^{\circ} \mathrm{C}$ in the absence and presence of A9Y3PPA.

\begin{tabular}{|c|c|c|c|c|c|c|c|}
\hline \multicolumn{6}{|c|}{ Tafel Data } & \multicolumn{2}{|c|}{ Linear Polarisation Data } \\
\hline $\begin{array}{c}\mathrm{C} \\
(\mathrm{mM})\end{array}$ & $\begin{array}{c}E_{\text {corr }} \\
\text { (mV/SCE) }\end{array}$ & $\begin{array}{c}I_{\text {corr }} \\
\left(\mathrm{mA} / \mathbf{c m}^{2}\right)\end{array}$ & $\begin{array}{c}\mathbf{b}_{\mathbf{a}} \\
\text { (V/dec) }\end{array}$ & $\begin{array}{c}-\mathbf{b}_{\mathrm{c}} \\
\text { (V/dec) }\end{array}$ & $\eta_{\text {pol } \%}$ & $\mathbf{R}_{\mathbf{p}}(\mathbf{o h m})$ & $\eta \mathbf{R p} \%$ \\
\hline Blank & -489 & 0.6282 & 0.076 & 0.096 & - & 29.36 & - \\
\hline 0.2 & -489 & 0.2627 & 0.076 & 0.094 & 58.18 & 69 & 57.75 \\
\hline 0.4 & -502 & 0.1209 & 0.061 & 0.087 & 80.75 & 129 & 77.20 \\
\hline 0.6 & -479 & 0.0729 & 0.077 & 0.101 & 88.40 & 261 & 88.76 \\
\hline 0.8 & -489 & 0.0678 & 0.076 & 0.086 & 89.21 & 258 & 88.64 \\
\hline 1.0 & -509 & 0.0323 & 0.075 & 0.083 & 94.86 & 531 & 94.47 \\
\hline
\end{tabular}

\subsection{AFM studies}

The surface morphology of carbon steel surface was evaluated by atomic force microscopy (AFM). The figure 9 (a-c) shows the surface (3D) morphology of the bare carbon steel surfaces, CS specimens without and with inhibitor in hydrochloric acid medium respectively.

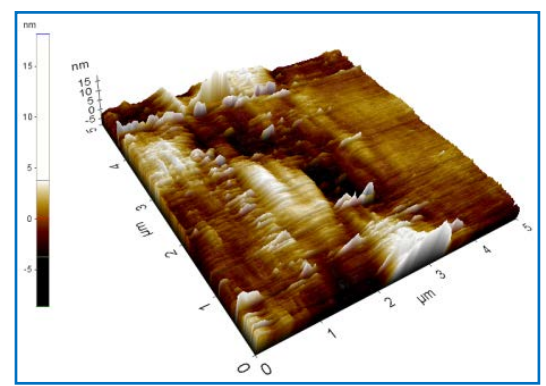

(a)

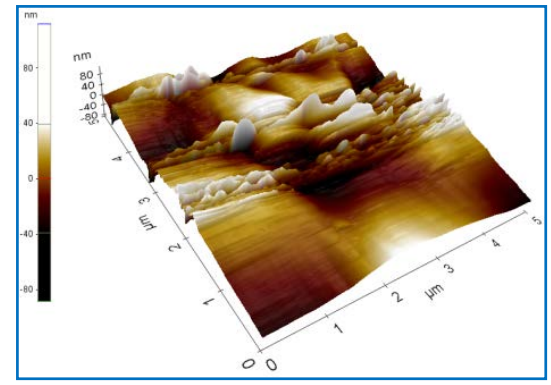

(b)

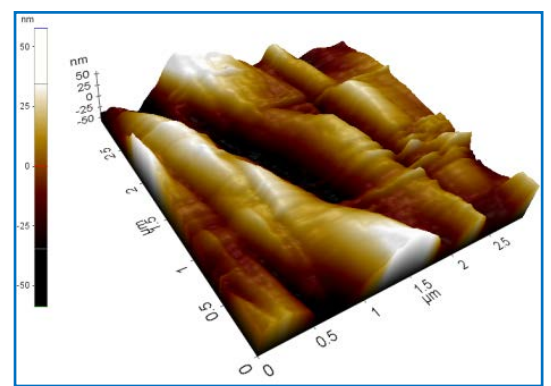

(c)

Fig. 9. AFM micrographs of carbon steel surface (a) Polished fresh specimens b) Immersed in $1 \mathrm{M} \mathrm{HCl}$ solution for $24 \mathrm{~h} \mathrm{c}$ ) Immersed in $1 \mathrm{M} \mathrm{HCl}$ solution containing 1mM A9Y3PPA for $24 \mathrm{~h}$. 
The average roughness of polished bare carbon steel surface (figure 9a), carbon steel in $1 \mathrm{M} \mathrm{HCl}$ without and with inhibitor (figure 9b-c) was calculated to be 1.39, 15.68 and $9.80 \mathrm{~nm}$ respectively. It is clearly from the figure 9b that the corroded carbon steel sample shows a rough surface due to acid corrosion. However in the presence of inhibitor, the rate of corrosion is suppressed and surface of the inhibited carbon steel specimens get smoothened as shown in figure 9c. The decrease in roughness was due to the formation of an adsorbed A9Y3PPA film on the carbon steel surface.

\subsection{Mechanism of Inhibition}

It is well known that the surface of the metal is positively charged in acidic media ${ }^{25}$. It is believed that the $\mathrm{Cl}^{-}$ions could be specifically adsorbed on the metal surface and creates an excess of negative charge on the surface. This will favour the adsorption of protonated Schiff base (A9Y3PPA ${ }^{+}$) on the surface ${ }^{26}$ and hence reduce the dissolution of Fe to $\mathrm{Fe}^{2+}$ (Fig.10).

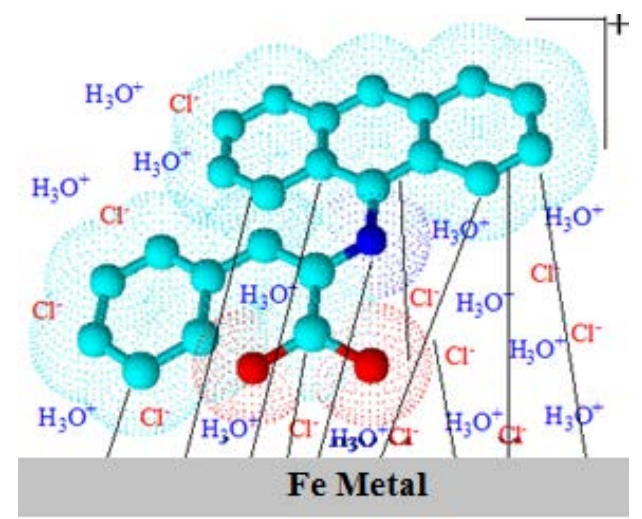

Fig. 10. Schematic representation of Mechanism of Inhibition

Besides this electrostatic interaction between the protonated Schiff base and the metal surface, other possible interactions are i) interaction of unshared electron pairs in the molecule with the metal ii) interaction of $\pi$-electrons with the metal and iii) a combination of types (i-ii) ${ }^{27,28}$. The $\pi$-electron cloud of the aromatic rings and the azomethine linkage also participate in the inhibition mechanism. Furthermore, the double bonds in the inhibitor molecule permit the back donation of metal d electrons to the $\pi^{*}$ orbital and this type of interaction cannot occur with amines ${ }^{29}$. This can be justified by the lower inhibition efficiency of the parent amine than that of Schiff base.

\section{Conclusions}

1. A9Y3PPA acts as good inhibitor for CS in $1 \mathrm{M}$ hydrochloric acid medium.

2. Inhibition efficiency increases with increase in concentration of inhibitor.

3. Compared to the parent amine and ketone, the Schiff base A9Y3PPA exhibited higher inhibition efficiency for CS corrosion.

4. The inhibition mechanism is explained by adsorption. The adsorption of A9Y3PPA obeys Langmuir adsorption isotherm.

5. The thermodynamic parameters calculated from the adsorption isotherms showed that both physisorption and chemisorption are involved in the inhibition process.

6. A9Y3PPA acts as a mixed type corrosion inhibitor for CS specimens in $1 \mathrm{M} \mathrm{HCl}$.

\section{Experimental}

\subsection{Inhibitor and Solutions}

The inhibitor used in this experiment was a Polynuclear Schiff base (A9Y3PPA) and obtained by the condensation of equimolar mixture of anthracene-9 $(10 \mathrm{H})$-one [ $\left.\mathrm{R}_{1}\right]$ and (s)-2-amino-3-phenyl propanoic acid $\left[\mathrm{R}_{2}\right]$ in ethanol. The reaction mixture was refluxed for 6 hours, cooled by keeping 
overnight, filtered, washed and dried (Scheme I). Anal.calcd for $\mathrm{C}_{23} \mathrm{H}_{19} \mathrm{NO}_{2}$ : C, 80.84; H, 5.56; N, $4.10 \%$. Found. C, 80.48; H, 5.23; N, 3.98\% ; m.p. $=243^{0} \mathrm{C}$; IR $(\mathrm{KBr}): v_{\mathrm{C}=\mathrm{N}}=1595 \mathrm{~cm}^{-1}, v_{\mathrm{COOH}}=$ $3380 \mathrm{~cm}^{-1} .{ }^{1} \mathrm{Hnmr}: \delta_{\mathrm{COOH}} 11.20 .{ }^{13} \mathrm{Cnmr}: \delta_{\mathrm{COOH}}=182.11, \delta_{\mathrm{C}=\mathrm{N}}=140.05 \mathrm{ppm}$. The aggressive solution of $1 \mathrm{M} \mathrm{HCl}$ was prepared by dilution of A.R grade $37 \%$ of $\mathrm{HCl}$ (Merck) with de-ionized water. Inhibitor solutions were prepared in the range, $0.2 \mathrm{mM}-1.0 \mathrm{mM}$ concentrations.

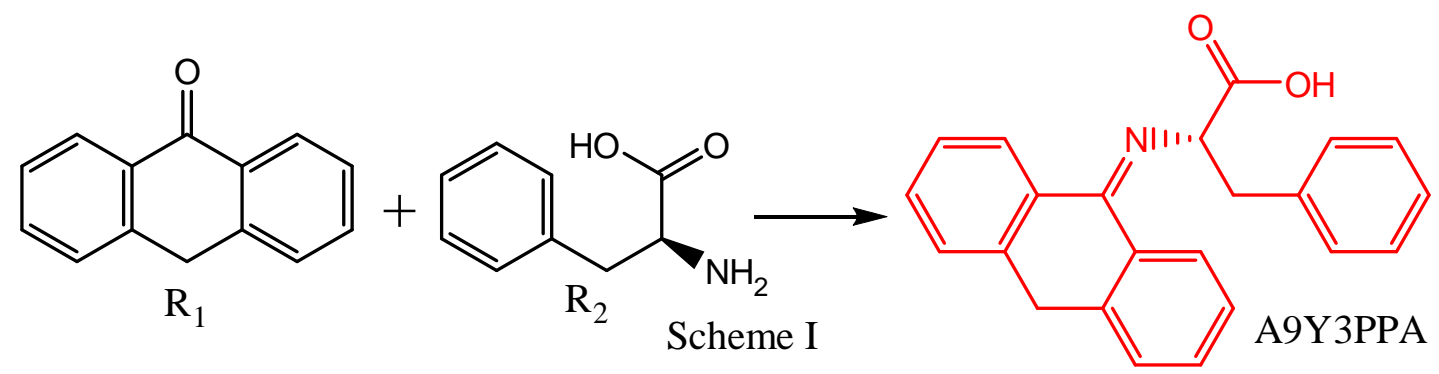

\subsection{Weight loss measurements}

Carbon steel specimens of dimension $1.5 \times 2 \times 0.1 \mathrm{~cm}$, having composition C, $0.5 \%$; Mn, $0.07 \%$; , 0.02\%; S, 0.015\%; Si, 0.02\% and rest Fe were cut and abraded with various grades of silicon carbide papers (200, 400, 600, 800, 1000, 1200 and 2000). The exact area and thickness of each coupon were measured and washed with soap water. Specimens were then degreased again with acetone and finally dried. After weighing, specimens were immersed in $50 \mathrm{ml}$ acid solutions (naturally aerated) at $30-60^{\circ} \mathrm{C}$ in the absence and presence of the inhibitor (A9Y3PPA) using hooks and fishing lines. Weight loss of metal specimens was noted after $24 \mathrm{~h}$. The experiments were carried out in duplicate and the average values were reported. The corrosion rate $(v)$ and the percentage of inhibition efficiency $\left(\eta_{w} \%\right)$ were calculated by the following equations ${ }^{30,31}$.

$$
\begin{aligned}
& v=\frac{W}{S t} \\
& \eta_{\mathrm{w}} \%=\frac{v_{0}-v}{v_{0}} \times 100
\end{aligned}
$$

where $\mathrm{W}$ is the weight loss ( $\mathrm{g})$ of specimen, $\mathrm{S}$ is the total area $\left(\mathrm{cm}^{2}\right)$ of specimens, $\mathrm{t}$ is the time of treatment $(24 \mathrm{~h}), v_{0}$ and $v$ are the corrosion rates $\left(\mathrm{mmy}^{-1}\right)$ of uninhibited and inhibited specimens respectively.

\subsection{Electrochemical Impedance Spectroscopy (EIS)}

The EIS measurements were performed in a three electrode cell assembly. Saturated calomel electrode (SCE) was used as the reference electrode. Platinum electrode having $1 \mathrm{~cm}^{2}$ area was taken as counter electrode. Metal specimens with an exposed area of $1 \mathrm{~cm}^{2}$ were used as the working electrode. The EIS experiments were carried out on an Ivium compactstat-e electrochemical system. 1 $\mathrm{M} \mathrm{HCl}$ (no stirring) was taken as the electrolyte and the working area of the metal specimens were exposed to the electrolyte for $1 \mathrm{~h}$ prior to the measurement. EIS measurements were performed at constant potential (OCP) in the frequency range from $1 \mathrm{KHz}$ to $100 \mathrm{mHz}$ with amplitude of $10 \mathrm{mV}$ as excitation signal. The percentage of inhibitions from impedance measurements were calculated using charge transfer resistance values by the following expression ${ }^{32}$

$$
\eta_{\text {EIS }} \%=\frac{R_{c t}-R_{c t}^{\prime}}{R_{c t}} X 100
$$

where $R_{c t}$ and $R^{\prime}{ }_{c t}$ are the charge transfer resistances of working electrode with and without inhibitor respectively. 


\subsection{Potentiodynamic Polarization Studies}

Electrochemical polarization studies on CS specimens in $1 \mathrm{M} \mathrm{HCl}$ with and without inhibitor were performed by recording anodic and cathodic potentiodynamic polarization curves. Polarization plots were obtained in the electrode potential range from -100 to $+100 \mathrm{mV}$ versus equilibrium potential (Ecorr) at a scan rate of $1 \mathrm{mV} / \mathrm{sec}$. Tafel polarization analysis were done by extrapolating anodic and cathodic curves to obtain corrosion current densities ( $\left.\mathrm{I}_{\text {corr }}\right)$. The percentage of inhibition efficiency $\left(\eta_{\text {pol\% }}\right)$ was evaluated from the measured $\mathrm{I}_{\text {corr }}$ values using the following relation ${ }^{33}$

$$
\eta_{\text {pol }} \%=\frac{I_{\text {corr }}-I^{\prime} \text { corr }}{I_{\text {corr }}} \mathrm{X} 100
$$

where $I_{\text {corr }}$ and I' corr are the corrosion current densities of the exposed area of the working electrode in the absence and presence of inhibitor respectively.

From the slope analysis of the linear polarization curves in the vicinity of corrosion potential of blank and different concentrations of the inhibitor, the values of polarization resistance $\left(\mathrm{R}_{\mathrm{p}}\right)$ in $1 \mathrm{M} \mathrm{HCl}$ solution were obtained. From the evaluated polarization resistance, the inhibition efficiency was calculated using the relationship

$$
\eta_{R_{p}} \%=\frac{R_{p}^{\prime}-R_{p}}{R_{p}^{\prime}} X 100
$$

where $\mathrm{R}_{\mathrm{p}}$ and $\mathrm{R}_{\mathrm{p}}$ are the polarization resistance in the presence and absence of inhibitor, respectively ${ }^{34}$.

\subsection{Atomic force microscopy}

Surface morphology of carbon steel specimen was investigated using atomic force microscopy (Park systems, XE-100 model). Contact mode was used with a scan rate of $0.8 \mathrm{~Hz}$ and the area of scan was $5 \mu \mathrm{m} \mathrm{X} 5 \mu \mathrm{m}$. After immersion in $1 \mathrm{M} \mathrm{HCl}$ solutions in the absence and presence of the inhibitor A9Y3PPA (1mM) for $24 \mathrm{~h}$ at $30^{\circ} \mathrm{C}$, the specimen were cleaned with distilled water, dried and used for AFM

\section{References}

1. James O., Oforka N. C., Abiola O. K. (2007) Inhibition of acid corrosion of mild steel by pyridoxal and pyridoxol hydrochlorides. Int. J. Electrochem. Sci., 2, 278-284.

2. Abd El-Maksoud S. A. (2008) The effect of organic compounds on the electrochemical behaviour of steel in acidic media. A review. Int. J. Electrochem. Sci., 3, 528-555.

3. Vinod P. R., Joby T. K., Shaju K. S., Aby P. (2013) Corrosion inhibition investigations of 3- acetylpyridine semicarbazone on carbon steel in hydrochloric acid medium. Res. Chem. Intermed., 40, 2689-2701. DOI 10.1007/s11164-013-1122-3

4. Ebenso E. E., Okafor P. C., Offiong O. E., Ita B. I., Ibok U. J., Ekpe U. J. (2001) Comparative investigation into the kinetics of corrosion inhibition of aluminium alloy AA 1060 in acidic medium. Bull. Elect. Chem., $17,459-464$.

5. Sethi T. A., Chaturvedi R. K., Upadyay, Marthur S. P. (2007) Corrosion inhibitory effects of some Schiff's bases on mild steel in acid media. J. Chil. Chem. Soc., 52, 1206-213.

6. Srivastva K. P., Kumar A., Singh R. (2010) Bivalent transition metal complexes of tridentate Schiff base ligands: an ecofriendly study. J. Chem. Pharm. Res. 2, 68-77.

7. Suraj B. A., Deshpande M. N., Kolhatkar D. G. (2012) Corrosion a universal environmental problem: a role of Schiff base metal complexes as inhibitors. J. Chem. Pharm. Res., 4, 1033-1035.

8. Aby P., Joby T. K., Vinod P. R., Shaju K. S. (2012) Electrochemical and Gravimetric corrosion Inhibition Investigations of A Heterocyclic Schiff Base Derived From 3-Formylindole. IOSR J. Appl. Chem., 1,17-23.

9. Deng S., Li X., Fu H. (2011) Alizarin violet 3B as a novel corrosion inhibitor for steel in $\mathrm{HCl}_{2} \mathrm{H}_{2} \mathrm{SO}_{4}$ solutions. Corros. Sci., 53, 3596-3602. 
10. Li X, Deng S, Fu H (2011) Blue tetrazolium as a novel corrosion inhibitor for cold rolled steel in sulfuric acid solution. Mater. Chem. Phys., 129, 696-700.

11. Shaju K. S., Joby T. K., Vinod P. R., Aby P. (2012) Synergistic Effect of KI on Corrosion Inhibition of Mild Steel by Polynuclear Schiff Base in Sulphuric Acid. ISRN Corrosion. DOI 10.5402/2012/425878.

12. Bouklah M., Hammouti B., Lagrenée M., Bentiss F. (2006) Thermodynamic properties of 2,5-bis(4ethoxyphenyl)-1,3,4-oxadiazole as a corrosion inhibitor for mild steel in normal sulfuric acid medium. Corros. Sci. 48, 2831-2842.

13. Cano E., Polo J. L., Iglesia A. L., Bastidas J. M. (2004) A study on the adsorption of benzotriazole on copper in hydrochloric acid using the inflection point of the isotherm. Adsorption, 10, 219-225.

14. Bentiss F., Lebrini M., Lagrenée M. (2005) Thermodynamic characterization of metal dissolution and inhibitor adsorption processes in mild steel/2,5-bis (n-thienyl)-1,3,4-thiadiazoles/ hydrochloric acid system. Corros. Sci., 47, 2915-2931.

15. Li W., He Q., Zhang S., Pei C., Hou B. (2008) Some new triazole derivatives as inhibitors for mild steel corrosion in acidic medium. J. Appl. Electrochem., 38, 289-295.

16. Bouklah M., Benchat N., Hammouti B., Aouniti A., Kertit S., Thermodynamic characterisation of steel corrosion and inhibitor adsorption of pyridazine compounds in $0.5 \mathrm{M} \mathrm{H}_{2} \mathrm{SO}_{4}$. Mater. Lett., 60,1901-1905.

17. Sathiya Priya A. R., Muralidharam V. S., Subramannia A. (2008) Development of novel acidizing inhibitors for carbon steel corrosion in 15\% boiling hydrochloric acid. Corrosion, 64, 541-552.

18. Azhar M. E., Mernari B., Traisnel M., Bentiss F., Lagrenée M. (2001) Corrosion inhibition of mild steel by the new class of inhibitors [2,5-bis(n-pyridyl)-1,3,4-thiadiazoles] in acidic media. Corros. Sci., 43, 22292238.

19. Yurt A., Balaban A., Ustün K. S., Bereket G., Erk B. (2004) Investigation on some Schiff bases as HCl corrosion inhibitors for carbon steel. Mater. Chem. Phys., 85, 420-426.

20. Macdonald J. R., Johnson W. B., Macdonald J. R. (1987) Theory in impedance Spectroscopy, John Wiley \& Sons New York NY USA.

21. Singh A. K., Shukla S. K., Singh M., Quraishi M. A. (2011) Inhibitive effect of ceftazidime on corrosion of mild steel in hydrochloric acid solution. Mater. Chem. Phys., 129, 68-76.

22. MaCafferty M., Hackerman N. (1972) Double layer capacitance of iron and corrosion inhibition with polymethylene diamines. J. Electrochem. Soc. 119,146-154.

23. Li X., Deng S., Fu H. (2009) Synergism between red tetrazolium and uracil on the corrosion of cold rolled steel in $\mathrm{H}_{2} \mathrm{SO}_{4}$ solution. Corros. Sci. 51, 1344-1355.

24. Ferreira E. S., Giacomelli C., Giacomelli F. C., Spinelli A. (2004) Evaluation of the inhibitor effect of Lascorbic acid on the corrosion of mild steel. Mater. Chem. Phys., 83, 129-134.

25. Shaju K. S., Joby T. K., Vinod P. R., Aby P. (2012) Electrochemical and surface morphological studies of carbon steel corrosion by a novel polynuclear Schiff Base in $\mathrm{HCl}$ solution. ISRN Electrochemistry. DOI.org/10.1155/2013/820548.

26. Bentiss F., Traisnel M., Lagrenée M. (2000) The substituted 1,3,4-oxadiazoles: a new class of corrosion inhibitors of mild steel in acidic media. Corros. Sci. 42,127-146.

27. Schweinsberg D. P., George G. A., Nanayakkara A. K., Steinert D. A., (1998) The protective action of epoxy resins and curing agents-inhibitive effects on the aqueous acid corrosion of iron and steel. Corros. Sci. 28, 33-42.

28. Shokry H., Yuasa M., Sekine I., Issa R. M., El-baradie H. Y., Gomma G. K. (1998) Corrosion inhibition of mild steel bySchiff base compounds in various aqueous solutions: part 1. Corros. Sci. 40, 2173-2186.

29. Singh A. K., Quraishi M. A. (2010) Inhibiting effects of 5-substituted isatin-based Mannich bases on the corrosion of mild steel in hydrochloric acid solution. J. Appl. Electrochem., 40, 1293-1306.

30. ASTM (1990) standard recommended practice for the laboratory immersion corrosion testing of metals. ASTM G-31-72, ASTM, Philadelphia, Pa, USA.

31. Emregul K. C., Atakol O. (2004) Corrosion inhibition of iron in $1 \mathrm{M} \mathrm{HCl}$ solution with Schiff base compounds and derivatives. Mater. Chem. Phys. 83, 373-379.

32. Raman A., Labine P. (1986) Reviews on Corrosion Inhibitor Science and Technology. NACE, Houston, Tex, USA.

33. Ashassi-Sorkhabi H., Shaabani B., Seifzadeh D. (2005) Effect of some pyrimidinic Shciff bases on the corrosion of mild steel in hydrochloric acid solution. Electrochim. Acta., 50, 3446-3452.

34. Elkadi L., Mernari B., Traisnel M., Bentiss F., Lagrenée M. (2000) The inhibition action of 3,6-bis(2methoxyphenyl)-1,2-dihydro-1,2,4,5-tetrazine on the corrosion of mild steel in acidic media. Corros. Sci. 42, 703-719. 